\title{
Bioética-Sociobiologia. \\ Neologismos oportunos? Interface da tecnociência com as ciências humanas e sociais
}

William Saad Hossne ${ }^{1}$

\section{Nos dicionários - Interface?}

Década de 1.970. Dois neologismos nascem; ambos com o elemento de composição "bios" (vida): Bioética e Sociobiologia. No vocábulo "Bioética", Bio inicia o neologismo e em Sociobiologia, Bio aparece ao final do neologismo.

Ambos levaram alguns anos para serem reconhecidos e recolhidos nos dicionários.

O curioso é que dentre mais de uma centena de vocábulos que se iniciam com o elemento "bio", no dicionário "Aurélio", o termo bioética não está consignado, na segunda edição de 1986 (aparece na terceira edição de 1999); também não consta o vocábulo Sociobiologia (figura na terceira edição -Ferreira, 1999). Está registrado, porém, o vocábulo Biosociologia: “Biosociologia - estudo das comunidades vivas como sistemas integrados".

No dicionário Houaiss (2001) estão catalogados mais de trezentos vocábulos que se iniciam com "bio", incluindo Bioética, Biosociologia e Sociobiologia.

"Bioética - estudo dos problemas e implicações morais despertadas pelas pesquisas científicas em biologia e medicina. A bioética abrange questões como a utilização de seres vivos em experimentos, a legitimidade moral do aborto ou da eutanásia, as implicações profundas das pesquisas e práticas no campo da genética, etc". "Sociobiologia - estudo comparativo da organização social dos animais, incluindo a do homem, especialmente em relação à sua base genética e à sua história evolutiva".

"Biosociologia - estudo das bases biológicas do comportamento social dos animais e por extensão, dos seres humanos; sociobiologia".

Verifica-se que bioética estaria vinculada à ética envolvida nas pesquisas científicas em biologia e medicina; trata-se de uma definição voltada às origens da expressão bioética, sim, porém, reducionista, já que bioética não está restrita apenas ao campo da pesquisa.

Os dois termos, Bioética e Sociobiologia, evocam, de imediato, a idéia de pluri e interdisciplinaridade e, sobretudo a "interface entre cultura científica [ou tecnocientífica] e cultura humanística". E este seria o fato auspicioso tão desejado. Com algumas variações de nomenclatura, nos ambientes acadêmico-universitários agrupam-se, genericamente, as várias disciplinas universitárias em ciências exatas

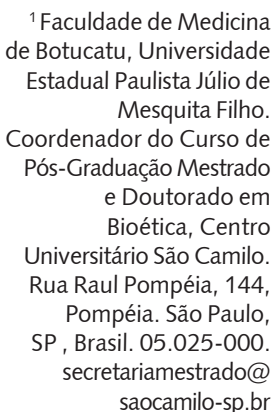

${ }^{1}$ Faculdade de Medicina Mesquita Filho. Coordenador do Curso de ação Mestrado Bioética, Centro São Camilo. Pompéla Sao , Brasil. 05.025-000 saocamilo-sp.br 
(e tecnológicas), ciências biológicas e ciências humanas e sociais. De acordo com BERNAL (1969, p.1060), na ordenação das ciências, colocam-se as ciências sociais no fim de "uma série que começa com as matemáticas, passa pela física e pela química até a biologia dos animais e depois à dos homens, à psicologia e, por fim, à sociologia." Ainda assim, costuma-se dividi-las em dois grandes campos, que muitos chamam de "cultura" (e daí para frente seguiremos esta esquematização), a cultura científica (área de tecnociências) de um lado e "cultura humanística" de outro.

Ao longo da história milenar da Universidade houve momentos em que as duas culturas estiveram mais ou menos afastadas. Com a revolução científica e com a criação da nova universidade (início do século XIX), tendo como emblema a fundação da Universidade de Berlim, a cultura científica (e no século XX, a tecnociência) foi integrada à universidade, até então voltada para a cultura humanística em sua quase totalidade.

As ciências experimentais se desenvolveram fora da universidade durante quase três séculos; seu abrigo foram as Academias e as Sociedades Científicas.

Ao final do século XVIII e início do século XIX, a universidade não podia mais voltar as costas para tais atividades; por outro lado, os cientistas buscavam sua inserção na universidade. Daí, seu ingresso na Universidade e a inclusão, nos estatutos da universidade, do dispositivo da indissociabilidade do ensino (vinculado, sobretudo à cultura humanística) e da pesquisa (vinculada â cultura tecnocientífica).

Essa indissociabilidade, até hoje, considerada ponto básico estatutário, não significou, porém, integração ampla das duas culturas, apesar das relações entre ciência e sociedade.

A propósito, vale referir o que escreve Bernal (1969, p.1286): "As relações entre a ciência e a sociedade são absolutamente recíprocas. Da mesma maneira que os acontecimentos sociais levam às transformações nas ciências, também as transformações sociais são, cada vez mais, provocadas pela ciência".

Apesar disso, a inter-relação entre as duas culturas não foi tão extensa, quanto deveria ser.

Houve mais inter-relações entre disciplinas de cada "cultura" do que entre disciplinas das duas culturas.

Como referido, pela sua composição, as duas novas expressões (bioética e sociobiologia) evocariam, de imediato, uma relação entre duas esferas (ou arenas) ou duas culturas: a da biologia (sentido amplo) e a das ciências humanas; em Bioética é evocada a relação das ciências biológicas (ciências da vida, da saúde e do meio ambiente) com a filosofia (em particular a ética) e em Sociobiologia, as ciências sociais, com as biológicas.

O que levou a criação dos dois neologismos? Qual o significado inicial de cada um? Após o nascimento, qual a evolução de cada um? Como estão aos quarenta anos? Qual o significado e a mensagem que deixaram? O que prometem para o futuro? E, sobretudo, "bioética" e "sociobiologia" conseguiram unir ou integrar, de maneira interdisciplinar a esfera tecnocientífica com a esfera humanística e cultural? Qual delas atingiu tal fim?

Neste sentido, na verdade, verificamos que vários outros vocábulos que se iniciam com "bio" abriam também perspectivas ou probabilidades de integração efetiva entre as duas esferas, a tecnocientífica e a humanística.

Assim, dos mais de trezentos verbetes com o elemento "bio" (Houaiss, 2001) selecionamos alguns, de profundo significado, mas que não levaram (e talvez nem fosse de se esperar) a tal integração. Assinalemos, à titulo de ilustração, os seguintes vocábulos:

Bioastronáutica, Bioastronomia, Biocibernética, Biofísica, Bioquímica, Biomatemática, Biomecânica, Biometeorologia, Biopolítica, Bioeletrônica, Bioengenharia, Bioestatística, Biogeoquímica, Biometria, Biontologia, Biônica.

Muitos destes termos caracterizam uma disciplina de fronteira - mas nenhum deles pretendia (talvez) levar à integração das duas esferas já referidas.

E Bioética e Sociobiologia, conseguiram? As palavras têm vida própria. Nascem, crescem e adquirem personalidade, algumas delas. Outras nascem e fenecem em pouco tempo. Outras banalizam-se e se transformam em rótulo, uma casca sem conteúdo. Outras há que mudam parcial ou totalmente de sentido, ganhando significado diverso daquele que a gestou. Outras já nascem com significado profundo e, rapidamente aglutinam pessoas e ideias, propiciam abertura de novos caminhos, abrem 
novas perspectivas, desencadeiam reformulações e inovações. É o caso da Bioética, podemos adiantar.

De qualquer modo, a evolução dos neologismos é repleta de vicissitudes e, na verdade, raramente ocorre de forma linear como esquematizado acima; o mais comum é um zig-zag.

\section{Nas bases de dados - sobrevida dos neologismos}

Vejamos um pouco tais vicissitudes da Sociobiologia e da Bioética. Para se ter uma ideia de como os dois vocábulos se inseriram na área acadêmica desde o seu nascimento, apresentamos no Quadro 1 o número de publicações (a partir de 1970), por década, em que figura, no título, o neologismo Sociobiologia (Biosociologia) e o neologismo Bioética. Os dados são das bases SPRINGER e MEDLINE.

Quadro 1. Sobrevida dos neologismos nas bases de dados

\begin{tabular}{|l|c|c|c|c|c|c|}
\hline & \multicolumn{3}{|c|}{ Base SPRINGER } & \multicolumn{3}{c|}{ Base MEDLINE } \\
\cline { 2 - 8 } & Sociobiologia & Biosociologia & Bioética & Sociobiologia & Biosociologia & Bioética \\
\hline Década de 1970 & 7 & 1 & - & 54 & 1 & 53 \\
\hline Década de 1980 & 22 & 1 & 4 & 51 & 2 & - \\
\hline Década de 1990 & 20 & 1 & 86 & 20 & 1 & 1.347 \\
\hline Década de 2000 & 19 & - & 298 & - & - & 130 \\
\hline Ano 2010 & 3 & - & 16 & 2 & - & 110 \\
\hline Ano 2011 & - & - & 65 & 140 & 4 & 2.796 \\
\hline Total & 71 & 3 & 469 & & & \\
\hline
\end{tabular}

${ }^{2}$ A palavra Bioética, no sentido atual, foi proposta por Potter, no início da década de

1970. Sabe se hoje que em 1927, Fritz Jahr

também empregou o vocábulo em outro sentido. A expressão

Sociobiologia ganhou vida após a publicação de Wilson (também na década de 1970); há citações dando conta de que a expressão também

foi empregada por $A$. Carrel, em 1936, segundo Guillebaud, que traz boa síntese da Sociobiologia.
Os dados mostram que a expressão Sociobiologia (e/ou biosociologia) figura, no título, em 74 publicações (14\%), e Bioética em 469 (86\%), na base Springer. Na base MEDLINE, Sociobiologia (e/ou biossociologia) aparece em 144 publicações (5\%) e Bioética em 2796 (95\%).

Quando se analisa o número de publicações por década, nota-se que o número de publicações com o neologismo Sociobiologia (e/ou biosociologia) vai diminuindo, enquanto o o neologismo Bioética vai aumentando de modo bem acentuado. Assim, na base Springer, 70\% das publicações em que figura o neologismo Sociobiologia ocorrem entre 1970 e a década 1990, isto é, apenas $30 \%$ das publicações mais recentes; no caso da Bioética os dados são $19 \%$ até a década de 1990 e $81 \%$ mais recentemente. Na base MEDLINE, os dados referentes ao mesmo período, mostram que, no caso da Sociobiologia somente $15 \%$ dos artigos foram publicados após a década de 1990, no caso da Bioética, 57\%.

O que levou Wilson a criar o neologismo Sociobiologia e Potter, o neologismo Bioética? ${ }^{2}$ 
De início, pela composição dos termos depreende-se que na Bioética "bios" foi "buscar" a "ética", ao passo que na Sociobiologia, a sociologia foi buscar o "bios" (isto é, as ciências biológicas).

A busca do encontro entre disciplinas diferentes (como é o caso, na bioética e na Sociobiologia) ocorre, em geral, quando surge uma "questão", um "problema", um "desafio", ou uma demanda externa, para a qual uma determinada disciplina não consegue, dentro dos seus próprios parâmetros ou cânones, resolver ou ao menos equacionar, como assinala Fourez (1995).

Essa disciplina busca outras e assim se inicia a multidisciplinaridade, que pode ficar aí restrita como pode caminhar para uma relação mais profunda entre as disciplinas, surgindo então, a interdisciplinaridade e a transdiciplinaridade. Em alguns dos casos, resolvida a "demanda", cada disciplina retorna ao seu berço, com ou sem alguma "incorporação" da(s) outra (s) disciplina (s). Outras vezes a inter-relação das disciplinas é mais profunda chegando a suscitar a ideia do nascimento, pela fusão das disciplinas, de uma "superciência nova".

No geral, isso não prospera. Nesses casos o que pode, de fato acontecer, é o surgimento de uma nova disciplina, ou melhor, uma nova área de conhecimento.

\section{Sociobiologia e Bioética - percurso e significado}

O neologismo Sociobiologia surgiu no meio acadêmico-universitário com a publicação do livro "Sociobiology - The New Synthesis" (1975), de Edward O. Wilson, considerado o pai da Sociobiologia, e se difundiu com outras publicações (Wilson, 1977, 1978, 2000)

O novo termo, desde o nascimento, vem causando controvérsias. (Bock, 1982; Ruse, 1983; Wallace, 1985). De fato, como o próprio autor assinala, houve os defensores e os críticos da Sociobiologia - não cabe aqui, analisar os aspectos doutrinários da Sociobiologia nem a análise dos argumentos de um lado e de outro. Wilson, respeitado entomologista americano, especialista em formigas e estudioso de sistemas sociais de insetos, ao criar o termo teve como objetivo estruturar uma nova disciplina, caracterizada no glossário de seu livro:

Sociobiology - the systematic study of the biological basis of all social behavior. Wilson pretendeu dar bases mais concretas (no sentido de ciência) à sociologia humana.

Com a expressão: "the new synthesis - aposto à Sociobiology" - o neologismo, ao contrário da Bioética, trouxe "síntese" e não "análise".

Ao que tudo indica, no caso da Sociobiologia a "demanda", na visão de Wilson, era a busca de estruturação de um arcabouço de sustentação (ou pensamentos) da sociologia (ciências sociais); Wilson foi buscar este arcabouço com base nas ciências biológicas. Isso já transparece na definição por ele dada à Sociobiologia: "estudo sistemático da base biológica de qualquer comportamento social... Uma das funções da Sociobiologia consiste, pois, em reformular os fundamentos das ciências sociais, de modo a permitir sua inclusão na Síntese Moderna".

Para ele, entrariam na "síntese" a genética (em geral), a genética de populações, a ecologia, a etologia, a sociobiologia e a antropologia. No caso da Sociobiologia não houve uma relação harmônica entre a cultura humanística e a tecnocientífica (no caso, biociências) o que houve não foi uma relação inter-pares, mas sim uma "imposição" dos parâmetros das ciências biológicas nas ciências sociais.

Já ao nascimento, colegas de Wilson (da Universidade de Harvard) criticaram a proposta da Sociobiologia, denunciando a concepção reducionista e determinista da Sociobiologia; alguns criticaram o "geneticismo" envolvido: a biologia e, em particular, os genes determinavam e explicavam tudo. Tudo no comportamento já estava determinado pela base biológica, o que foi aproveitado para fins políticos, levando à própria segregação e discriminação racial. Aproveitando-se dessa concepção determinista e reducionista, alguns educadores encontraram argumentos para a segregação racial nas escolas para crianças.

Na visão de Guillebaud (2008), a Sociobiologia foi apropriada pela extrema direita para fins políticos, educacionais e econômico-financeiros. Tudo poderia se justificar pelo determinismo genético. 
No caso da Sociobiologia, portanto, foi dada hegemonia, com imposição das ciências biológicas; não se tratava de harmonia entre disciplinas, mas de "sufoco" sem diálogo e sem enriquecimento mútuo. Foi utilizada, instrumentalizada, a serviço de interesses políticos e de ideologias de interesses de grupos. Não houve aproximação e nem mesmo qualquer relacionamento harmônico e frutífero entre as duas esferas já referidas. Não houve aglutinação, houve discórdias.

Feneceu, sem frutos? Ao final de 25 anos, por ocasião da publicação comemorativa, reconhece-se que persistem as controvérsias.

Já na Bioética, o fenômeno foi outro e o significado para as culturas humanista e tecnocientífica foi completamente oposto.

A Revolução Molecular, iniciada na década de 1950, já aos vinte anos de evolução (década de 1970) trouxe profundas repercussões nas biociências e nas biotecnologias, abrindo perspectivas espetaculares para a humanidade, ao mesmo tempo em que gerava apreensões profundas, pela possibilidade, pelo uso inadequado, de destruição da própria humanidade e das "futuras gerações'".

Potter, oncologista norte-americano, de origem europeia, preocupado com o fato, criou o neologismo Bioética; neologismo carregado porém, de profundo significado.

Basicamente, Potter, em seu livro "Bioethics- Bridge to the Future" (início da década de 1970) propunha a criação de nova área de conhecimento, marcada pelo encontro entre a cultura humanística e a tecnociência: os fatos da ciência (biociências e biotecnologias) deveriam ser trazidos à consideração da cultura humanística, para a reflexão crítica, pluralista, interdisciplinar, enfatizando a ética (Potter, 1971).

A Bioética nascia com a preocupação ética na área das ciências da vida, da saúde e do meioambiente, incluindo a interface entre essa área e as duas culturas.

A Bioética não é a ética das áreas biológicas pensada pela sua própria comunidade científica específica. É a ética multi, inter e transdisciplinar, convocando, para reflexão ética, os diversos segmentos da comunidade científica e cultural, bem como os diversos segmentos da própria sociedade.

No caso da Bioética foram as ciências biológicas que buscaram as ciências humanísticas e buscaram de modo a estabelecer um relacionamento profundo, equilibrado, harmônico e enriquecedor.

Aos quarenta anos de vida, a Bioética está consolidada como área de conhecimento, situada nas fronteiras de interdisciplinaridade. É uma área de conhecimento não só pela abrangência de seu campo de atuação, mas pelas suas próprias características de atuação.

O desenvolvimento da Bioética passou pela fase paradigmática e com a implantação da pósgraduação (stricto-sensu) atinge o que Fourez (1995) denomina fase pós-paradigmática, na qual se inicia o processo de formação de sua própria comunidade científico cultural.

Pelo exposto, verifica-se que as implicações da Sociobiologia e da Bioética nas esferas científicas e culturais foram diferentes. Na Sociobiologia, pela sua gênese e concepção, não ocorreu a integração, tão desejável, entre as duas culturas. Pelo contrário: imposição, instrumentalização, determinismo, reducionismo e desvirtuamento foram características da trajetória do neologismo.

\section{Bioética - ponte entre "culturas". Interface.}

Na Bioética, tanto no campo teórico quanto no prático, se implantou e se consolidou o encontro feliz e produtivo entre as duas culturas. No prefácio do livro "Bioethics-Bridge to the Future", Potter (1971, p.5) refere "o propósito deste livro é contribuir para o futuro da espécie humana ao promover a formação de nova disciplina, a disciplina de Bioética". E prossegue:

Se há duas culturas que parecem incapazes de falar uma com a outra - ciência e humanidades - e se isto é parte da razão que parece por em dúvida o futuro, então possivelmente, nós possamos construir uma ponte para o futuro, construindo a disciplina Bioética como uma ponte entre estas duas culturas. 
Em 1988, Potter publicou o livro "Global Bioethics", inserindo já na capa, logo abaixo do título do livro, o seguinte: "Bio-ethics-Biology combined with diverse humanistic knowledge forging a science that sets a system of medical and environmental priorities for acceptable survival".

Do exposto, vale destacar que o vocábulo Bioética, na opinião de Potter, enfatiza os seguintes pontos:

- bioética visa integrar as duas culturas;

- não se trata apenas de analisar o sistema médico, mas todas as ciências biológicas, incluindo meioambiente (físico e social);

- do lado das humanidades, com destaque à ética, inclui-se a participação

de todas as áreas das ciências humanas e sociais;

- do lado da "cultura da ciência", inclui-se a participação de todos os ramos da ciência e não apenas as ciências biológicas, pois bios é aqui entendida como vida, em todos os sentidos.

Potter insiste em dizer que na Bioética, pluralista e multidisciplinar, é necessário trazer os fatos biológicos à reflexão por parte de todos as demais disciplinas, sobretudo da cultura humanística.

Verifica-se, pois que o vocábulo bioética vem carregado de significados ou mensagens.

Há que se destacar que Bioética se propõe a ser analítica, interrogando as "duas culturas".

As palavras-chave são: análise e reflexão crítica, integrando e harmonizando as diversas áreas do conhecimento.

O que nos interessa é explorar, ainda que superficialmente, a mensagem do neologismo e como isso pode ter interferido na integração entre as "duas culturas".

Bioética e Sociobiologia são dois neologismos nascidos à mesma época (década de 1970) compostos por bio - e uma disciplina da esfera das humanidades (ética no caso da bioética e sociologia, no caso da sociobiologia).

Em princípio seria de se esperar (e seria desejável) que a integração ocorresse nos dois casos. Não foi o que ocorreu.

Na bioética as duas "culturas" são chamadas para integração, mantendo as disciplinas seus parâmetros, sua autonomia e participando, num movimento de análise; de reflexões críticas.

Na proposta de Wilson, a biologia se funde hegemonicamente com a sociologia - não há propriamente uma integração entre as duas culturas. A proposta é de fusão estruturada e baseada nos fenômenos biológicos. Não há o "chamamento" para "análise e reflexão crítica", como acontece com o neologismo bioética, cujo significado mais relevante é o da interação entre as citadas "duas culturas".

Este fato merece alguns comentários.

Entre o final do século VII A.C. e o século V A.C. (e início do século IV A.C) ocorreu na Grécia talvez um dos fenômenos mais marcantes e profundos na história da civilização ocidental. Neste período, há cerca de 25 séculos, nasceram "trigêmeos", que se desenvolveram e se firmaram no mundo, sempre interagindo entre si: a filosofia, a medicina e a democracia. Nenhum deles teria evoluído como evoluiu, sem a inter-relação com seus "irmãos".

A filosofia, a partir de Tales passa pela fase cosmológica (é a physis) pela antropológica (com a ética e a teoria do conhecimento, com Sócrates) pela fase helenística romana, em interação com a medicina.

A medicina surge como tekhne iatrike* (técnica médica) com Hipócrates e com a implantação do raciocínio clínico e a ética de seu juramento, em íntima relação com a filosofia.

Sobre essas inter-relações, Jaeger (1986, p.687), com sua autoridade de respeitável helenista diz textualmente: "Pode-se afirmar sem exagero que sem o modelo da Medicina seria inconcebível a ciência ética de Sócrates, a qual ocupa o lugar central nos diálogos de Platão. De todas as ciências humanas então conhecidas, incluindo a Matemática e a Física, é a Medicina a mais afim da ciência ética de Sócrates".

Quanto ao papel e à importância da democracia nesta inter-relação vale lembrar que foi da "assembléia de guerreiros" (Chauí, 1944, p.42) e da palavra diálogo, pública e equalitária (isegoria e isonomia) que nasce a polis e é inventada a política.

Para a filosofia e para a medicina, na visão hipocrática (sobretudo na ética da relação médicopaciente), a implantação da democracia, como instituição social e política foi fundamental. Com Clistenes e Péricles, democracia, filosofia e medicina mutuamente se apoiam e se consolidam. 
Cabe enfatizar que neste fenômeno dos "trigêmeos", ciência, técnica e cultura se encontram e se entrelaçam. Esta "junção" não ocorreu quando as ciências (e logo depois, as tecnologias) se desenvolveram, mas quando outro marco importante na história da civilização ocidental - o nascimento das ciências experimentais e do método científico, com Galileu e Leonardo da Vinci, Francis Bacon, Descartes.

Com Galileu (1564-1642) nascem as ciências experimentais, berço dos demais ramos das ciências e a ciência se desenvolve rápida e progressivamente, mas o faz sem inter-relação com as ciências humanas. Na verdade, sem relacionamento algum com a grande instituição nascida na Idade Média - a Universidade.

\begin{abstract}
De fato, o desenvolvimento das ciências (como hoje as reconhecemos) se deu fora da Universidade, sem outra inter-relação; os cientistas se abrigaram e se encontraram nas Academias de Ciência - fora da Universidade, a qual sequer as considerava merecedoras de maior atenção. Foi nas Academias (como sociedades científicas) dos Lincei (Roma, 1600-30), de Cimento (Florença, 1651-67), na Royal Society (Londres, 1662) e na Academia Royale des Sciences (França, 1666) que a ciência se desenvolveu. (Bernal, 1969, p.449)
\end{abstract}

Não se pode dizer que não houve relação da área científica em desenvolvimento com a área das humanas e sociais, tanto que Bernal (1969) insere um tópico denominado a "Revolução Humanista nas atitudes e nas ideias", ao se referir à revolução científica que então ocorreu entre os sécs. XVI e XVIII. É bem verdade que a inter-relação das ciências com as humanidades foi buscada com a elaboração da Enciclopédia Francesa, inclusive com a participação de cientistas e humanistas. Já no final do século XVIII e no início do século XIX, a Universidade, que voltara as costas para as "ciências", não poderia ignorar a importância e o alcance da revolução científica. Por outro lado, os cientistas da área física, da química, da experimentação, buscavam se inserir na Universidade. Este foi também um momento importante, enfrentado de modo diverso na França, na Inglaterra, em Portugal.

Dentro da nossa linha voltada para a inter-relação das ciências com as outras áreas, interessa focalizar o acontecido na Alemanha, com a fundação da Universidade de Berlim (início do século XIX). Essa universidade foi criada pregando a indissociabilidade do ensino e da pesquisa na universidade, procurando receber e abrigar cientistas - um resgate após cerca de 200 e tantos anos.

Na nova Universidade procurava-se o pesquisador mais que o clássico professor, mais o laboratório de pesquisa que a sala de aula. Desta forma, a ciência (e a tecnologia) se integram na Universidade e de certa forma com as áreas sociais e humanísticas. Na verdade, esta integração não foi tão profunda. A interdisciplinaridade resultante da integração ocorreu entre disciplinas da própria área científica.

Desde então, tem-se procurado a inter-relação das duas esferas (ciências e tecnologia, de um lado, e ciências humanas de outro) numa lembrança do que ocorreu na Grécia clássica.

Neste pano de fundo surgem, na década de 1970, os dois neologismos objeto deste artigo, induzindo a inter-relação entre as duas esferas, favorecendo a integração - sempre lembrada e pouco efetivada.

\title{
Bioética. Situação ilustrativa. Legado.
}

Com a Bioética estamos vivenciando um momento muito rico que faz lembrar o grande acontecimento referido anteriormente: o tríplice nascimento, os "irmãos gêmeos", na Grécia, há mais de 25 séculos. Naquela ocasião nasciam a filosofia, a medicina e a democracia. em conjunto e em inter-relação. Esta inter-relação fez uma grande diferença.

Hoje, com o advento da Bioética, procura-se a inter-relação não apenas da filosofia com a medicina e com a democracia - o fenômeno oferecido pela Bioética é mais amplo: a inter-relação é com todas as ciências humanas e sociais, não apenas com a medicina, mas com todas as ciências de saúde e da biologia, entre si e com as ciências exatas; não apenas com a isegoria e a isonomia dos guerreiros, mas com toda a sociedade (o sujeito e a coletividade) participando. 
Ilustra bem o fenômeno a experiência brasileira, a partir do final da década de 1990, com as resoluções referentes à ética na pesquisa envolvendo seres humanos.

Essas resoluções tiveram origem bioética, para cuja elaboração contribuíram grupos tipicamente interdisciplinares, envolvendo pesquisadores da área da tecnociência e das ciências humanas e sociais; tiveram conceituação bioética, um sistema operacional tipicamente "bioético" e controle (social) também de características bioéticas.

Tome-se como ponto de referências os comitês institucionais (CEP) e a Comissão Nacional de Ética em Pesquisa (CONEP). São colegiados datados de "múnus público", de natureza essencialmente bioética. Os comitês institucionais têm a composição interdisciplinar, pois não podem ter mais da metade de seus membros pertencentes à mesma profissão; a outra metade é composta por pessoas de diversas áreas da saúde, das ciências exatas e das ciências humanas e devem contar com, pelo menos, um representante da comunidade de usuários.

De acordo com as suas características (e para isso existe liberdade de atuação) a instituição compõe seu comitê, podendo inclusive criar-se mais de um comitê. Assim, em Faculdade de Medicina, o CEP poderá contar com até metade de seus membros médicos; em Faculdade da área de ciências humanas poderá contar com até metade seus membros dessa área. Assegura-se, assim, a interdisciplinaridade, unindo representantes da área tecnocientífica (não apenas biológica) e a humanístico-cultural.

Ressaltamos que o convívio com profissionais de diferentes áreas, conjugando a duas culturas -a científica e a humanística - é extremamente importante, enriquecedor e produtivo. E reafirmamos que a Bioética é responsável pelo tríplice renascimento da medicina, filosofia e democracia, em conjunto e em inter-relação.

Saibamos aproveitar e usufruir o que a Bioética nos traz e saibamos encontrar o melhor caminho - o caminho da sabedoria; sinalizado pela interface e pela integração da tecnociência com as ciências humanas e sociais.

\section{Referências}

BERNAL, L.D. Ciência na História. v.2.Lisboa: Livros Horizonte, 1969.

BOCK, K. Natureza humana e história: uma réplica à Sociobiologia. Rio de Janeiro: Zahar, 1982.

CHAUÍ, M. Introdução à história da filosofia. v.1. São Paulo: Cia. das Letras, 1994. FERREIRA, A.B.H. Dicionário da língua portuguesa. Rio de Janeiro: Nova Fronteira, 1999

FOUREZ, G. A construção das ciências. São Paulo: Unesp, 1995. cap.5. p.103-44.

GREGORY, M.S.; SILVERS, A.; SUTCH, D. Sociobiology and human nature: an interdisciplinary. Critique and defense. San Francisco: JOSSEY-BASS, 1978.

GUILLEBAUD, J.C. O princípio da humanidade. São Paulo: Idéias e Letras, 2008.

HOUAISS, A. Dicionário Houaiss da língua portuguesa. Rio de Janeiro: Objetiva, 2001. 
JAEGER, W. Paidéia. Brasília: Martins Fontes, 1986.

JAHR, F. Bio-Ethik. Kosmos, v.24, p.2-4, 1927.

POTTER, V.R. Global Bioethics. East Lansing: Miichigan State University Press, 1988.

Bioethics: bridge to the future. Englewood Cliffs: Prentice Hall,1971.

RUSE, M. Sociobiologia: senso ou contra senso. São Paulo: EDUSP, 1983.

WALLACE, R.A. Sociobiologia: o fator genético. São Paulo: IBRASA, 1985.

WILSON, E.O. Sociobiology: the new synthesis. 27.ed. Cambridge: Havard University Press, 1999.

Introduction: what is Sociobiology. In: GREGORY, M.S.; SILVERS, A.; SUTCH, D. Sociobiology and human nature: an interdisciplinary. Critique and defense. San Francisco: Jossey-Bass, 1978.

What is Sociobiology. Society, v.15, n.6, p.10-4, 1977. 
O artigo focaliza a criação dos neologismos Bioética e Sociobiologia, analisando esses vocábulos que, pela sua composição, evocam relações entre ciências biológicas e ciências humanas (ética e sociologia). Destaca que esses dois neologismos já nasceram com profundos significados, mas em sentidos diferentes. Ressalta a importância da bioética na integração das culturas científica e humanística, para além das disposições estatutárias universitárias. Conclui indicando que a Bioética traz uma mensagem sugestiva de como criar mecanismos e condições para enfrentar os desafios que os avanços científicos, inexoráveis, nos lançam.

Palavras-chave: Bioética. Sociobiologia. Cultura científica. Cultura humanística.

\section{Bioethics-Sociobiology. Opportune neologisms? Interfaces between tecnoscience and human and social sciences}

The article focuses on the creation of the neologisms Bioethics and Sociobiology, analyzing these two words which due to their composition evoke relations between biological sciences and human studies (ethics and sociology). Highlights that these two neologisms, in fact, were born already loaded by deep meanings, but in different senses. Emphasizes the importance of bioethics in the integration of scientific and humanistic cultures, beyond university statuary regulations. Concludes that Bioethics conveys also a suggestive message about how to create mechanisms and conditions for facing the challenges which scientific advancements, in their inexorability, present.

Keywords: Bioethics. Sociobiology. Scientific culture. Humanistic culture.

\section{Bioética-Sociobiología. Neologismos oportunos?} Interfaces entre la tecnociencia y las ciencias humanas y sociales

El artículo se centra en la creación de neologismos Bioética y Sociobiología y en el análisis de estas palabras que, gracias a su composición evocan relaciones entre las ciencias biológicas y las humanidades (ética y sociología). Destaca que estos dos neologismos nacen ya cargados de hondos significados, pero en distintos sentidos. Afirma ser la Bioética efectivamente un puente a la junción harmónica de la cultura de la "tecnociencia" y la cultura de los estudios humanísticos e sociales, más allá de las regulaciones estatutarias universitarias. Concluye indicando que la bioética también trasmite un sugestivo mensaje a cerca la manera de crear mecanismos y condiciones como para afrontar los retos que los avanzos científicos, en su inexorabilidad, nos presentan.

Palabras clave: Bioética. Sociobiología. Cultura científica. Cultura humanística. 